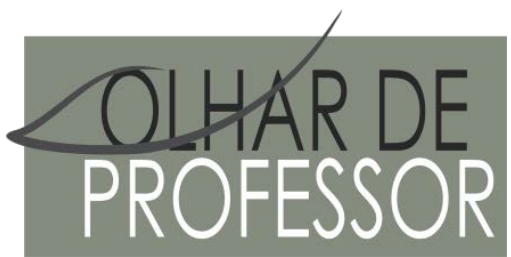

DOI: 10.5212/OLHARPROFR.v.21i1.0006

\title{
UM ESTUDO SOBRE TEORIAS DE APRENDIZAGEM NAS ÁrEAS DE EDUCAÇÃo MATEMÁtICA E EDUCAÇ̃̃O/ENSINO
}

\author{
A STUDY ON LEARNING THEORIES IN THE AREAS OF MATHEMATICAL EDUCATION AND \\ EDUCATION/IEACHING \\ UN ESTUDIO SOBRE TEORÍAS DE APRENDIZAJE EN LAS ÁrEAS DE EDUCACIÓN MATEMÁTICA Y \\ EDUCACIÓN/ENSEÑANZA
}

\author{
ANGELA MENEGHELLO PASSOS* \\ MARINEZ MENEGHELLO PASSOS ${ }^{\text {* }}$ \\ SERGIO DE MELLO ARRUDA ${ }^{* * *}$
}

\begin{abstract}
Resumo: Nesta pesquisa de cunho qualitativo, objetivou-se caracterizar referências e autores que ancoram a aprendizagem da matemática atualmente no Brasil e, também, as referências e autores que fundamentam o campo da aprendizagem na área de Educação/Ensino. Os dados foram coletados a partir dos artigos publicados em seis revistas nacionais no triênio 2013-2015. Para o desenvolvimento dos procedimentos analíticos foi utilizada a Análise de Conteúdo. A primeira evidência a que se chegou foi que um pouco mais de um quarto dos artigos, publicados nas revistas selecionadas, enfatizaram a aprendizagem, ratificando a importância do tema na área educacional. Contudo, dos dados selecionados e do que foi levantado, pode-se observar que, atualmente, no Brasil, não existem, de forma geral, referências e nem autores que se destacam como representativos para a criação de um aporte teórico sobre aprendizagem na área de Educação Matemática e na área de Educação/Ensino. Acredita-se que essa divergência de referências e autores no campo da aprendizagem ocorre pelo fato de as pesquisas acontecerem em uma diversidade de contextos, em que cada um possui seu arcabouço teórico para estudar a aprendizagem.
\end{abstract}

Palavras-chave: Teorias de aprendizagem. Educação Matemática. Educação. Ensino. Análise de Conteúdo.

\begin{abstract}
In this qualitative research, we aimed to characterize references and authors that anchor the learning of mathematics currently in Brazil, as well as the references and authors that base the field of learning in the area of Education/Teaching. Data were collected from papers published in six Brazilian journals in the triennium 2013-2015. For the development of analytical procedures, Content Analysis was used. The first evidence was that a little more than a quarter of the articles, published in the selected journals, emphasized learning, confirming the importance of the topic in the educational area. However, from the data selected and from what was raised, it can be observed that, currently, in Brazil, there are in general no references and no authors that

\footnotetext{
* Doutora em Ensino de Ciências e Educação Matemática pela Universidade Estadual de Londrina. Instituto Federal do Paraná (IFPR) - Câmpus Londrina, PR. E-mail: angelamp@sercomtel.com.br

*** Doutora em Educação Para a Ciência pela Universidade Estadual Paulista Júlio de Mesquita Filho. Universidade Estadual de Londrina. E-mail: marinezmp@sercomtel.com.br

*** Doutor em Educação pela Universidade de São Paulo. Universidade Estadual de Londrina. E-mail: sergioarruda@uel.br
} 
stand out as representative for the creation of a theoretical framework on learning in the area of Mathematics Education and in the area of Education/Teaching. It is believed that this divergence of references and authors in the field of learning occurs due to the fact that research takes place in a diversity of contexts, each of which has its theoretical framework to study learning.

Keywords: Learning theories. Mathematical Education. Education. Teaching. Content analysis.

Resumen: En esta investigación de cuño cualitativo, se objetivó caracterizar referencias y autores que anclan el aprendizaje de las matemáticas actualmente en Brasil y, también, las referencias y autores que fundamentan el campo del aprendizaje en el área de Educación / Enseñanza. Los datos fueron recolectados a partir de los artículos publicados en seis revistas nacionales en el trienio 2013-2015. Para el desarrollo de los procedimientos analíticos se utilizó el Análisis de Contenido. La primera evidencia a la que se llegó fue que un poco más de un cuarto de los artículos publicados en las revistas seleccionadas, enfatizaron el aprendizaje, ratificando la importancia del tema en el área educativa. Sin embargo, de los datos seleccionados y de lo que fue levantado, se puede observar que, actualmente, en Brasil, no existen, de forma general, referencias y ni autores que se destacan como representativos para la creación de un aporte teórico sobre aprendizaje en el área de Educación Matemática y en el área de Educación / Enseñanza. Se cree que esta divergencia de referencias y autores en el campo del aprendizaje ocurre por el hecho de que las investigaciones ocurren en una diversidad de contextos, en que cada uno posee su marco teórico para estudiar el aprendizaje.

Palabras claves: Teorías de aprendizaje. Educación Matemática. Educación. Enseñanza. Análisis de contenido.

\section{INTRODUÇÃO}

Considerando que as teorias de aprendizagem e de ensino são essenciais quando se estabelece uma relação entre elas e a formação inicial, a formação continuada e a prática docente do professor em exercício, torna-se evidente que merecem atenção especial dos professores e dos pesquisadores da área educacional. Diante desse fato e mediante um estado de curiosidade, indagou-se primariamente: por meio de quais referências a área de Educação Matemática "fala” sobre a aprendizagem? As áreas de Educação/Ensino e Educação Matemática compactuam a respeito dessas referências?

Neste artigo traz-se resultados de uma investigação que buscou evidenciar essas referências, com a intenção de constituir um acervo sobre a temática aprendizagem que pudesse orientar seções de estudo e desenvolvimento de pesquisas.

Porém, outra questão de primeira ordem precisa ser elucidada: o que vem a ser uma teoria de aprendizagem?

Conforme definido por Moreira (2011, p. 12), tem-se que:

Uma teoria de aprendizagem é, então, uma construção humana para interpretar sistematicamente a área de conhecimento que chamamos aprendizagem. Representa o ponto de vista de um autor/pesquisador sobre como interpretar o tema aprendizagem, quais as variáveis independentes, dependentes e intervenientes. Tenta explicar o que é aprendizagem, por que funciona e como funciona.

No último século, várias foram as teorias de aprendizagem construídas para sistematizar o conhecimento. Entre elas, têm-se, conforme Moreira (2011, p. 18), as que estão fundamentadas:

- nos comportamentos observáveis e que possuem como conceitos básicos o estímulo, o comportamento, o condicionamento, o reforço positivo;

- na cognição em que os conceitos básicos se apresentam no esquema de assimilação, no signo, no instrumento, no modelo mental, no subsunçor, na aprendizagem significativa, no construto pessoal; 
- na pessoa com algumas ideias básicas no aprender a aprender, na liberdade para aprender, no ensino centrado no aluno, no crescimento pessoal, na consciência crítica, na autonomia, entre outros.

Diante desses vários enfoques teóricos sobre a aprendizagem, esta investigação foi idealizada para buscar referências que ancoram a aprendizagem da matemática atualmente no Brasil e, também, as referências que fundamentam o campo da aprendizagem na área de Educação/Ensino.

Assim, percorreu-se um caminho que indicasse as referências que a área de Educação Matemática e a área de Educação/Ensino consideram em seus artigos publicados e que trazem a aprendizagem como foco da discussão ou de manifestações. Para tal encaminhamento, buscou-se por periódicos nacionais representativos dessas duas áreas que pudessem trazer essas informações.

Em resumo, pode-se indicar que esta investigação teve como objetivo: identificar referências a respeito de teorias de aprendizagem, utilizadas na atualidade no Brasil, que possam se caracterizar como representativas nas áreas de Educação Matemática e Educação/Ensino. Diante desse panorama, a questão de pesquisa levantada para conduzir a realização deste estudo pode ser assim formulada: Atualmente, no Brasil, existem referências sobre teorias de aprendizagem que se destacam como representativas nas áreas de Educação Matemática e Educação/Ensino?

\section{FUNDAMENTAÇÃO TEÓRICO-METODOLÓGICA}

A seguir encontra-se uma descrição dos referenciais teóricos e metodológicos que fundamentaram esta investigação assumida como de cunho bibliográfico, o que garante uma visão sistematizada daquilo que foi desenvolvido na área de Educação Matemática e na área de Educação/Ensino nos últimos anos com relação à temática aprendizagem.

Essa vertente sustentada por levantamentos bibliográficos remete à caracterização de um “estado da arte" ou "estado do conhecimento", como indica Ferreira (2002, p. 257), são importantes espaços para o desenvolvimento de pesquisas, que objetivam mapear e discutir determinadas produções acadêmicas em diferentes campos do conhecimento.

Esses inventários, ou seja, essas descrições ou essas avaliações minuciosas provenientes desses movimentos investigativos levam à compreensão das temáticas privilegiadas em diferentes épocas e lugares, fato que justifica a realização de balanços relativos à área do conhecimento em questão.

As considerações conclusivas daquilo que foi interpretado pelo pesquisador possui a finalidade de reconhecer temáticas de relevância, organizar informações que poderiam sustentar outras investigações, além de possibilitar a evidenciação de lacunas ou hiatos a serem pesquisados.

Diante disso, adota-se como metodologia de coleta de dados e de pesquisa a análise textual, com destaque e convergência para a análise de conteúdo (AC), tomando como teóricos Bardin (2011), Moraes (1999, 2003), Navarro e Díaz (1999). Discorre-se, a seguir, um pouco sobre o referencial que proporcionou esse desenvolvimento e trouxe algumas possibilidades conclusivas.

Aceitando a análise de conteúdo por um método de investigação para um campo de pesquisa que se depara com uma grande diversidade de questões - a Educação, a Educação Matemática e, por conseguinte, a aprendizagem - sua característica de adaptação, como acena a literatura, faz com que se acomode de forma adequada na exploração qualitativa das mensagens e das informações que se procura compreender, as quais, como já indicado, estão presentes nos artigos que irão constituir o acervo e, em um momento posterior, o corpus - "[...] conjunto de documentos tidos em conta para serem submetidos aos procedimentos analíticos.” (BARDIN, 2011, p. 126).

A análise de conteúdo constitui uma metodologia de pesquisa usada para descrever e interpretar o conteúdo de toda classe de documentos e textos. Essa análise, conduzindo a descrições sistemáticas, qualitativas ou quantitativas, ajuda a 
reinterpretar as mensagens e a atingir uma compreensão de seus significados num nível que vai além de uma leitura comum. (MORAES, 1999, p. 9).

Cabe ainda destacar que nesta proposta de pesquisa considera-se a análise de conteúdo como uma proposta teórica, que se acomoda como método de coleta e de análise de dados. A seguir, apresentam-se alguns aspectos metodológicos que norteiam esse referencial, entre eles: a preparação do material a ser pesquisado; a definição de unidades de análise ou de registro que podem evidenciar significados, temáticas, códigos; a categorização, que tem por finalidade agrupar os dados mediante critérios definidos durante o processo de desenvolvimento da investigação; a descrição, que assume o papel de apresentar, primariamente, na forma de um texto-síntese, os resultados da pesquisa; e, na etapa final, a interpretação, fase em que a pesquisa atinge um grau de compreensão mais profundo do conteúdo dos documentos analisados e o pesquisador produz seu metatexto, em que comunica seus pareceres sobre o objeto de pesquisa.

É importante lembrar, também, que a definição e a delimitação coerente do corpus (a matériaprima a ser estudada) são primordiais para que os resultados da pesquisa sejam relevantes. Por isso, procura-se lançar mão de critérios para levantar a amostragem dos textos, neste caso os artigos, que serão utilizados na análise, principalmente para que se possa garantir a validade dos resultados e a representatividade do fenômeno em estudo.

Tendo-se o corpus em mãos, o primeiro procedimento interpretativo é a desconstrução dos textos. Nela se destacam os elementos que o constituem. Como em um processo de fragmentação, cujo objetivo é perceber os sentidos do texto em seus pormenores, em seus detalhes. Essa divisão deve ser proposta pelo pesquisador e é dela que vão resultar as unidades de análise, que também são denominadas por Navarro e Díaz (1999) “unidades de registros”.

Estando atento ao contexto que proporcionou a construção de cada um dos fragmentos, o próximo passo é construir códigos que indiquem a origem de cada unidade. Quanto maior ou menor a amplitude das unidades de fragmentação, uma quantidade maior ou menor de códigos precisa estar indexada a elas, isto é, quanto mais se fragmenta, mais códigos precisam indicar de onde provêm tais unidades de análise ou de registros.

Feita a desconstrução, tem-se o início de outro procedimento, denominado unitarização.

A unitarização é um processo que produz desordem a partir de um conjunto de textos ordenados. Torna caótico o que era ordenado. Nesse espaço uma nova ordem pode constituir-se à custa da desordem. O estabelecimento de novas relações entre os elementos unitários de base possibilita a construção de uma nova ordem, representando uma nova compreensão em relação aos fenômenos investigados. (MORAES, 2003, p. 196).

Posteriormente à unitarização, inicia-se o processo de categorização, momento em que o pesquisador é levado a estabelecer relações vinculadas aos resultados do procedimento anterior. A categorização consiste em agrupar elementos semelhantes criados na fase de construção das unidades de análise ou de registros, destacando que isso irá gerar conjuntos de elementos com significação próximos e que, em geral, serão nominados e estão relacionados de forma direta com os objetivos de pesquisa.

Isso posto, inicia-se a elaboração de um texto-síntese, com características descritivas e que contribui para comunicar previamente algumas das considerações a que o movimento interpretativo conduziu o pesquisador.

Por fim, tem-se a última etapa procedimental indicada na análise de conteúdo, a elaboração do metatexto produzido pelo pesquisador e que

[...] consiste, pues, en una determinada transformación del corpus, operada por reglas definidas, y que debe ser teóricamente justificada por el investigador a través de una interpretación adecuada. Desde este punto de vista, el AC debe entenderse como un conjunto de mecanismos capaces de producir preguntas, y como una receta para obtener respuestas. O, dicho de outro modo, ha de concebirse como un 
procedimiento destinado a desestabilizar la inteligibilidad inmediata de la superficie textual, mostrando sus aspectos no directamente intuibles y, sin embargo, presentes. (NAVARRO; DÍAZ, 1999, p. 182).

Esse processo de produção não se dá em uma única vez, não é fruto de um movimento único e contínuo sobre a matéria-prima em análise. É fruto de aproximações e afastamentos dos textos analisados, de olhares abrangentes, de momentos nos quais não se domina o compreendido e se busca o aprendizado - "é um processo vivo, um movimento de aprendizagem aprofundada sobre os fenômenos investigados.” (MORAES, 2003, p. 203).

\section{O CONTEXTO DA PESQUISA}

Nesta investigação foi realizado um inventário, que se pode denominar por estado do conhecimento, a respeito das referências sobre teorias de aprendizagem utilizadas na atualidade no Brasil. Inicialmente foi realizado um levantamento relativo às referências sobre as teorias de aprendizagem da matemática em artigos publicados, nos anos de 2013, 2014 e 2015 , em revistas nacionais que já foram selecionadas e que passaram por uma análise em Passos (2009a) e que são representativas da área de Educação Matemática. São elas:

- Bolema: Boletim de Educação Matemática - publicação do Programa de Pós-Graduação em Educação Matemática da Unesp. Rio Claro - SP.

Com a intenção de disseminar a produção científica em Educação Matemática ou áreas afins, o BOLEMA publica artigos, ensaios e resenhas, cujo foco relaciona-se ao ensino e à aprendizagem de Matemática ou ao papel da Matemática e da Educação Matemática na sociedade.

(http://www.periodicos.rc.biblioteca.unesp.br/index.php/bolema/index. Acesso em: 14 dez. 2016)

- Boletim Gepem - publicação do Grupo de Estudos e Pesquisas em Educação Matemática da UFRRJ. Seropédica - RJ.

O Boletim GEPEM é uma publicação semestral e acolhe, com vistas à divulgação, artigos (oriundos de pesquisa ou ensaios) ou comunicações de experiência (teoricamente fundamentadas) em aula que possam contribuir para o progresso da Educação Matemática ou para a troca de experiências e ideias entre pesquisadores, educadores e professores de Matemática.

(http://www.ufrrj.br/SEER/index.php?journal=gepem\&page=about\&op=editorialPolicies\#focusAn dScope. Acesso em: 14 dez. 2016.)

- Zetetiké - publicação institucional da Faculdade de Educação da Universidade Estadual de Campinas em parceria editorial com a Universidade Federal Fluminense. Campinas - SP.

A Zetetiké [...] tendo como objetivo contribuir, de um lado, para o desenvolvimento da pesquisa na Área da Educação Matemática e, de outro, para a formação de pesquisadores dessa Área, mediante intercâmbio e divulgação de pesquisas e estudos realizados por educadores matemáticos vinculados a instituições brasileiras ou estrangeiras.

(http://periodicos.sbu.unicamp.br/ojs/index.php/zetetike. Acesso em: 14 dez. 2016.)

O mesmo movimento investigativo indicado anteriormente foi utilizado para levantar um estado do conhecimento relativo às referências das teorias de aprendizagem na área de Educação. Inicialmente, foram consultados todos os periódicos nacionais qualisados pela Capes como A1 (Qualis 2014) na área de Educação, nos anos 2013, 2014 e 2015. Como ocorreu um excesso de periódicos e consequentemente de artigos, foi realizado um ajuste nesse processo de escolha.Diante do exposto foram consultados os artigos dos periódicos nacionais qualisados pela Capes como A1 na área de Educação e também na área de Ensino (Qualis 2014). Os periódicos selecionados foram: 
- Cadernos Cedes - publicação do Centro de Estudos Educação e Sociedade da Unicamp. Campinas - SP.

Os Cadernos CEDES são publicações de caráter temático, dirigidas a profissionais e pesquisadores da área educacional, com o propósito de abordar questões que se colocam como atuais e significativas neste campo de atuação.

(http://www.cedes.unicamp.br/publicacoes/11. Acesso em: 14 dez. 2016.)

- Revista Ciência \& Educação - publicação do Programa de Pós-Graduação em Educação para a Ciência da Unesp. Bauru - SP.

A Revista Ciência \& Educação tem como missão publicar artigos científicos sobre resultados de pesquisas empíricas ou teóricas e ensaios originais sobre temas relacionados à Educação Científica. Entende-se por pesquisa em Educação Científica as investigações que gerem conhecimentos, por exemplo, sobre o ensino e a aprendizagem de Ciências, Física, Química, Biologia, Geociências, Educação Ambiental, Matemática e áreas afins. A revista tem, ainda, como responsabilidade disseminar a pesquisadores, professores e alunos dos diversos níveis de ensino, bem como aos interessados em geral, a produção nacional e internacional nesta área de pesquisa. (http://www.unesp.br/prope/revcientifica/CienciaEducacao/Historico.php. Acesso em 14 dez. 2012.)

- Revista Ensaio: Avaliação e Políticas Públicas em Educação - publicação da Fundação CESGRANRIO. Rio de Janeiro - RJ.

Ensaio é um veículo de divulgação de pesquisas, levantamentos, estudos, discussões e outros trabalhos críticos no campo da educação, concentrando-se nas questões de avaliação e políticas públicas e enfatizando as experiências e perspectivas brasileiras. Ensaio é pluralista, do ponto de vista das ideias e das escolas de pensamento; interdisciplinar, do ponto de vista das preocupações e metodologias empregadas por seus colaboradores, acolhendo ou solicitando trabalhos sobre uma larga multiplicidade de temas.

(http://revistas.cesgranrio.org.br/. Acesso em 14 dez 2016.)

A revista BOLEMA: Boletim de Educação Matemática, também faz parte dessa relação de periódicos nacionais qualisados pela Capes como A1 na área de Educação e de Ensino (Qualis 2014), mas por se tratar de uma revista da área de Educação Matemática ela foi incluída na primeira parte do inventário, junto com os outros periódicos da área de Educação Matemática que foram analisados.

Resumindo, foram selecionadas seis revistas, todas disponibilizadas de forma online, três revistas da área de Educação Matemática: Bolema, Gepem e Zetetiké; e três da área de Educação: Cedes, Ciência \& Educação e Ensaio. Dessa forma inicia-se uma nova fase da investigação: selecionar os artigos cuja temática principal e/ou secundária, segundo Passos (2009a), fosse a aprendizagem. Para isso, buscou-se uma forma de levantamento de dados que apontasse o que foi publicado nos artigos, segundo o tema sobre o qual esta pesquisa se debruçou.

O procedimento metodológico para a seleção dos artigos seguiu o descrito em Passos (2009b), p. 28-29), em que palavras ou expressões foram assumidas como ferramentas iniciais de busca nos títulos, palavras-chave e resumo dos artigos. De posse dos artigos foram identificadas as referências relativas às teorias de aprendizagem neles destacadas. 


\section{APRESENTAÇÃOE ANÁLISE DOS DADOS}

Após uma leitura "flutuante" de alguns artigos das revistas selecionadas,as palavras aprendizagem, aprender (e suas conjugações) e aprendizado, foram assumidas como ferramentas de busca dos artigos sobre aprendizagem nos seis periódicos escolhidos. Foram lidos todos os títulos, resumos e palavras-chave dos artigos no período estabelecido e os que possuíam uma ou mais palavras escolhidas como ferramenta de busca foram selecionados para posterior análise. Veja a seguir informações quantitativas a respeito das revistas e dos artigos resultantes dessa interpretação inicial.

Quadro 1 - As revistas e os artigos em números

\begin{tabular}{|c|c|c|c|c|}
\hline Revistas & $\begin{array}{c}\text { Quantidade de } \\
\text { exemplares }\end{array}$ & $\begin{array}{c}\text { Total de } \\
\text { artigos }\end{array}$ & $\begin{array}{c}\text { Total de artigos } \\
\text { selecionados }\end{array}$ & $\begin{array}{c}\text { Porcentagem de } \\
\text { artigos selecionados }\end{array}$ \\
\hline Bolema (B) & 9 & 174 & 56 & $32,2 \%$ \\
\hline Gepem (G) & 6 & 47 & 12 & $25,5 \%$ \\
\hline Zetetiké (Z) & 6 & 43 & 9 & $20,9 \%$ \\
\hline $\begin{array}{c}\text { Subtotal (Educação } \\
\text { Matemática) }\end{array}$ & 21 & 264 & 77 & $29,2 \%$ \\
\hline Cedes (Ce) & 10 & 62 & 12 & $19,35 \%$ \\
\hline Ciência \& Educação (Ci) & 12 & 180 & 63 & $35 \%$ \\
\hline Ensaio (E) & 12 & 105 & 15 & $14,3 \%$ \\
\hline $\begin{array}{c}\text { Subtotal } \\
\text { (Educação/Ensino) }\end{array}$ & 34 & 347 & 90 & $25,9 \%$ \\
\hline Total & 55 & 611 & 167 & $27,3 \%$ \\
\hline
\end{tabular}

Apesar de esta pesquisa ser de cunho qualitativo, informações quantitativas, como as expostas no Quadro 1, dão uma visão geral do cenário investigativo e da amostragem dos textos que serão analisados. Dados como esses também são utilizados para delimitar o corpus e garantir a validade dos resultados e a representatividade do fenômeno estudado.

O lado quantitativo refere-se aos dados numéricos dos quais lançamos mão para direcionar nossas conclusões - ainda que estas não sejam e nem mesmo as pretendamos definitivas. A quantidade, nesse caso, manteve-se como guia, nunca como determinante e em nenhum momento lançamos mão do rigor como classicamente conhecido pelas abordagens positivistas. (GARNICA; PEREIRA, 1996, p. 61).

Desse quadro verifica-se que foram observadas 55 revistas, com um total de 611 artigos, dos quais, de acordo com a metodologia escolhida, 167 foram selecionados para análise, o que representa 27,3\% do total. Diante desses valores, tem-se que um pouco mais de um quarto dos artigos publicados nessas revistas enfatizam o tema aprendizagem, mostrando uma tendência dessas áreas em pesquisar ou manifestar-se sobre aprendizagem, fato que corrobora com as indagações primárias que se teve.

A partir dos 167 artigos selecionados iniciou-se a segunda fase da pesquisa: identificar referências sobre aprendizagem nos artigos das revistas da área de Educação Matemática e da área de Educação/Ensino. Nessa fase, as mesmas ferramentas de busca ${ }^{1}$ foram utilizadas, só que agora em todo o artigo, selecionando os parágrafos ou frases que possuíam uma ou mais unidades de busca e que indicavam alguma referência e, na sequência, destacava-se a referência indicada no texto. Veja a seguir um exemplo: zetetiké v. 21 n. $4020131^{2}$. Nele a unidade de busca encontrada no trecho

\footnotetext{
${ }^{1}$ Nos artigos de língua estrangeira as ferramentas de busca foram traduzidas para o idioma do artigo.

${ }^{2}$ Código que significa: revista Zetetiké, volume 21, número 40, ano 2013, artigo 1 da seleção.
} 
destacado é 'aprender' e as referências Deleuze 2006a, 2006b. O extrato apresentado a seguir, encontra-se no artigo em questão (p.109):

Diversos conceitos da filosofia de Gilles Deleuze têm inspirado nossos escritos. Mencionamos, com certa brevidade, o de "aprender" (Deleuze, 2006a, 2006b), que ocupa um lugar de destaque nas nossas produções. (BAMPI et al., 2013).

Como explicitado, os autores deste artigo, Bampi e seus colaboradores, assumem o "aprender", segundo Deleuze (2006a, 2006b). De posse dessa informação, buscou-se na lista das referências do artigo em análise a remissão da citação. O resultado está exposto a seguir:

DELEUZE, G. Diferença e repetição. Tradução: Luiz Orlandi e Roberto Machado. 2. ed. Rio de Janeiro: Graal, 2006a.

DELEUZE, G. Proust e os signos. Tradução: Antonio Piquet e Roberto Machado. 2. ed. Rio de Janeiro: Forense Universitária, 2006b.

Além de situações como estas, foram selecionadas também as referências do artigo que possuíam no título alguma das unidades de busca e que não foram selecionadas no procedimento anterior. Observe um exemplo: ciedu v. 19 n. $0120132^{3}$.

MERCADO, L. P. L. Integração de mídias nos espaços de aprendizagem. Em Aberto, Brasília, v.21, n.79, p.17-44, 2008.

No caso dessa referência selecionada, o que foi considerado para sua inclusão na listagem foi a palavra “aprendizagem” em seu título, a qual fazia parte dos nossos disparadores de busca.

Um a um os 167 artigos passaram por esses procedimentos. No Quadro 2 tem-se algumas informações quantificadas a respeito das referências selecionadas a partir dos 77 artigos da área de Educação Matemática e dos 90 artigos da área de Educação/Ensino.

Quadro 2 - Quantidade de referências selecionadas nos artigos

\begin{tabular}{|c|c|c|c|c|c|c|c|c|c|}
\hline Revistas & $\mathrm{B}$ & $\mathrm{G}$ & $\mathrm{Z}$ & $\begin{array}{c}\text { Subtotal } \\
\text { Educação } \\
\text { Matemática }\end{array}$ & $\mathrm{Ce}$ & $\mathrm{Ci}$ & $\mathrm{E}$ & $\begin{array}{c}\text { Subtotal } \\
\text { Educação/ } \\
\text { Ensino }\end{array}$ & Total \\
\hline $\begin{array}{c}\text { Quantidade de } \\
\text { referências }\end{array}$ & 307 & 79 & 71 & 457 & 44 & 483 & 90 & 617 & 1074 \\
\hline
\end{tabular}

Em cada área, as referências componentes de uma listagem única foram colocadas em ordem alfabética, em busca daquelas que se destacassem como representativas quando o assunto é aprendizagem. Qual foi a surpresa encontrada: a maior repetição em Educação Matemática no triênio 2013-2015 foi três vezes, isto é, 0,72\% de uma lista composta por 457 referências. A referência que mais se repetiu em Educação/Ensino no mesmo triênio foi oito vezes, ou seja, 1,30\% em um total de 617 referências. Agrupando (457 com 617) passou-se a ter uma listagem com 1074 referências, na qual a maior repetição continua sendo a de oito vezes, que passa a representar $0,74 \%$ do total. Diante desses fatos, surge então uma nova indagação: o que se evidenciou é representativo ou não? Pensa-se que não, todavia, como justificar?

Em função desse último questionamento, aplicou-se, nesses resultados, o teste para diferença entre proporções ao nível de significância de 5\%. Com ele verificou-se que:

- $\quad$ as proporções (percentuais) de referências citadas nos periódicos da área da Educação Matemática não diferiram significativamente entre si, sendo que a referência mais frequente

${ }^{3}$ Código que significa: revista Ciência \& Educação, volume 19, número 01, ano 2013, artigo 2 da seleção. 
teve representatividade de 0,66\% do total de citações (457 citações), indicando que não há uma referência em destaque;

- $\quad$ as proporções (percentuais) de referências citadas nos periódicos da área da Educação/Ensino diferiram apenas entre a mais citada (oito citações) e a menos citada (uma citação), ou seja, a referência com maior frequência (1,30\% - oito citações) não diferiu das demais (0,32\% - duas citações), indicando que não há uma referência em destaque;

- $\quad$ as proporções (percentuais) de referências citadas nos periódicos das duas áreas (Educação Matemática e Educação/Ensino) diferiram apenas entre a mais citada (oito citações) e a menos citada (uma citação), ou seja, a referência com maior frequência $(0,74 \%$ - oito citações) não diferiu das demais (0,19\% - duas citações), indicando que não há uma referência em destaque.

De forma geral, a partir das verificações realizadas, em relação à frequência das referências e o teste de diferença entre proporções, constatou-se que nenhuma referência se destaca de forma significativa, cujos percentuais são muito baixos em relação ao total de referências elencadas sobre a temática aprendizagem. A partir desse panorama, não foi possível encontrar referências que se destacassem como representativas para a constituição de um acervo ou de um aporte teórico sobre aprendizagem nas áreas selecionadas que orientasse os estudos e as pesquisas em idealização.

Diante do exposto, traçou-se um novo caminho em busca de uma representatividade no campo da aprendizagem. Um questionamento surgiu: será que um ou mais autores podem se destacar no campo da aprendizagem em uma das áreas ou em ambas? Assim, os olhares se concentraram nos autores das referências selecionadas, isto é, não se estava considerando mais unicamente a referência, mas sim os diversos autores que podem dela fazer parte, não necessariamente como nome primeiro e os diversos títulos em que esse autor possa estar implicado.

Nesse novo levantamento foram encontrados os seguintes resultados:

- na área de Educação Matemática observando as revistas Bolema, Gepem e Zetetiké, no triênio 2013-2015, o autor com maior repetição apareceu nove vezes, isto é, 1,97\% em um total de 457 referências - listado a seguir para exemplificar o movimento de seleção, a forma de apresentação está idêntica à exposta no artigo e a indexação ao artigo encontra-se entre parênteses (Z6-2), neste caso o código é relativo à revista Zetetiké v. 23 n. 44 2015:

Ponte, J. P. Da formação ao desenvolvimento profissional. In: Actas do ProfMat98. Lisboa: APM, 1998. p.27-44. (Z6-2)

Ponte, J. P. Gestão curricular em Matemática. In: GTI (ed.). O professor e o desenvolvimento curricular. Lisboa: APM, 2005. p.11-34. (Z6-1)

Ponte, J. P. Gestão curricular em Matemática. In: GTI (ed.). O professor e o desenvolvimento curricular. Lisboa: APM, 2005. p.11-34. (Z6-2)

PONTE, J. P. Investigar, ensinar e aprender. Actas do ProfMat. Lisboa APM, 2003. p.25-39 (CD). (G3-4)

PONTE, J. P. O novo programa de Matemática como oportunidade de mudança para os professores do Ensino Básico. Revista Interacções, Lisboa, v.5, n.12, p.96-114, 2009. Disponível em: http://www.eses.pt/interaccoes. Acesso em: 10 ago. 2011. (B9-7)

PONTE, J. P. Problemas e investigaciones en la actividad matemática de los alumnos. In: GIMÉNEZ, J.; SANTOS, L.; PONTE, J. P. (coord.). La actividad matemática en el aula. Barcelona: Graó, 2004. p.25-34. (B3-2)

PONTE, J. P.; BAPTISTA, M.; VELEZ, I.; COSTA, E. Aprendizagens profissionais dos professores de Matemática através dos estudos de aula. Pesquisas em Formação de Professores na Educação Matemática, [S. l.], n.5, p.7-24, 2012. (Z6-2) 
PONTE, J. P.; MATOS, J. F. Processos cognitivos e interacções sociais nas investigações matemáticas. In: ABRANTES, P.; LEAL, L. C.; PONTE, J. P. (ed.). Investigar para aprender matemática. Lisboa: Projecto MPT e APM, 1996. p.119-138. (B2-9)

PONTE, J.; OLIVEIRA, H. Remar contra a maré: a construção do conhecimento e da identidade profissional na formação inicial. Revista de Educação, Lisboa, v.11, n.2, p.145-163, 2002. (B7-6)

- na área de Educação/Ensino tendo como base as revistas Cedes, Ciência \& Educação e Ensaio, no mesmo triênio, o autor de maior ocorrência apareceu 11 vezes, ou seja, 1,78\% em um total de 617 referências;

VYGOTSKI, L. S. A construção do pensamento e da linguagem. São Paulo: Martins Fontes, 2001. (Ci2-3)

VYGOTSKI, L. S. A construção do pensamento e da linguagem. São Paulo: Martins Fontes, 2001. (Ci3-2)

VYGOTSKY, L. Pensamento e linguagem. 3. ed. São Paulo: M. Fontes, 1991. (Ci8-6)

VYGOTSKY, L. S. A construção do pensamento e da linguagem. São Paulo: Martins Fontes, 2001. (Ci12-4)

VYGOTSKY, L. S. Pensamento e linguagem. 2. ed. São Paulo: Martins Fontes, 1998b. (Ci12-4)

VYGOTSKY, L. S. Pensamento e Linguagem. 3. ed. São Paulo: Martins Fontes, 1993. (Ce7-1)

VYGOTSKY, L. S. Pensamento e linguagem. São Paulo: Martins Fontes, 1993. (Ci10-2)

VYGOTSKY, L. S. A formação social da mente. 4. ed. São Paulo: Martins Fontes, 1991. (Ce7-1)

VYGOTSKY, L. S. A formação social da mente. 6. ed. São Paulo: Martins Fontes, 1998. (Ci1-7)

VYGOTSKY, L. S. A formação social da mente: o desenvolvimento dos processos psicológicos superiores. 6. ed. São Paulo: Martins Fontes, 1998a. (Ci12-4)

VYGOTSKY, L. S. Fundamentos da defectologia. Havana: Pueblo y Education, 1995. (Obras completas, tomo 5). (Ci8-2)

- reunindo os autores das duas áreas, o que mais se repetiu foi 14 vezes, o que representa 1,3\% do total de 1074 referências e novamente a remissão é a Vygotsky.

VYGOTSKI, L. S. A construção do pensamento e da linguagem. São Paulo: Martins Fontes, 2001. (Ci2-3)

VYGOTSKI, L. S. A construção do pensamento e da linguagem. São Paulo: Martins Fontes, 2001. (Ci3-2)

VYGOTSKY, L. Pensamento e linguagem. 3. ed. São Paulo: M. Fontes, 1991. (Ci8-6)

VYGOTSKY, L. S. A construção do pensamento e da linguagem. São Paulo: Martins Fontes, 2001. (Ci12-4)

VYGOTSKY, L. S. A formação social da mente. 4. ed. São Paulo: Martins Fontes, 1991. (Ce7-1)

VYGOTSKY, L. S. A formação social da mente. 6. ed. São Paulo: Martins Fontes, 1998. (Ci1-7)

VYGOTSKY, L. S. A formação social da mente. 6. ed. São Paulo: Martins Fontes, 2002. (G4-2)

VYGOTSKY, L. S. A Formação social da mente. São Paulo: Martins Fontes, 1994. (B7-5)

VYGOTSKY, L. S. A formação social da mente: o desenvolvimento dos processos psicológicos superiores. 6. ed. São Paulo: Martins Fontes, 1998a. (Ci12-4) 
VYGOTSKY, L. S. Fundamentos da defectologia. Havana: Pueblo y Education, 1995. (Obras completas, tomo 5). (Ci8-2)

VYGOTSKY, L. S. Pensamento e linguagem. 2. ed. São Paulo: Martins Fontes, 1998b. (Ci12-4)

VYGOTSKY, L. S. Pensamento e linguagem. 3. ed. São Paulo: Martins Fontes, 1993. (Ce7-1)

VYGOTSKY, L. S. Pensamento e linguagem. São Paulo, Martins Fontes, 1993. (B2-4)

VYGOTSKY, L. S. Pensamento e linguagem. São Paulo: Martins Fontes, 1993. (Ci10-2)

Nesses dados também foi aplicado o teste para diferença entre proporções ao nível de significância de 5\%, e verificou-se que:

- $\quad$ as proporções (percentuais) de autores citados nos periódicos da área da Educação

Matemática não apresentaram diferença significativa entre proporção igual ou superior a 0,66\% (duas citações) e a maior proporção de 1,97\% (nove citações). Indicando que não há um autor em destaque;

- as proporções (percentuais) de autores citados nos periódicos da área da Educação/Ensino não apresentaram diferença significativa entre proporção igual ou superior a 0,49\% (três citações) e a maior proporção de 1,78\% (11 citações). Indicando que não há um autor em destaque;

- $\quad$ as proporções (percentuais) de autores citados nos periódicos das duas áreas (Educação Matemática e Educação/Ensino) não apresentaram diferença significativa entre proporção igual ou superior a $0,56 \%$ (seis citações) e a maior proporção de 1,30\% (14 citações). Indicando que não há um autor em destaque.

De forma análoga, a partir das verificações realizadas, em relação à frequência dos autores e o teste de diferença entre proporções, constatou-se que nenhum autor se destaca de forma significativa, cujos percentuais são muito baixos em relação ao total de autores citados. Percebeu--se que a representatividade em relação aos autores seguiu o mesmo padrão das referências: baixo índice de repetição. Dessa forma, também não foi possível encontrar autores que se destacassem como representativos para a elaboração de uma lista de autores que pudessem constituir determinado acervo para estudo e desenvolvimento de pesquisa.

Retomando os dados, nota-se que essa divergência de referências e autores no campo da aprendizagem pode-se dar pelo fato de as pesquisas ou manifestações apresentadas nos artigos ocorrerem em uma diversidade de contextos, em que cada um possui seu arcabouço teórico para estudar a aprendizagem ou "falar" sobre ela.

Na área de Educação Matemática essa variedade de contexto e/ou cenários investigativos foi verificada a partir de uma leitura e acomodação dos fragmentos textuais selecionados durante a tomada de dados nas revistas Bolema, Gepem e Zetetiké. A seguir são indicados vários contextose/ou cenários que emergiram dos trechos dos artigos que fazem parte do corpus analisado. Logo a seguir, têm-se dois extratos que exemplificam esses resultados. 
1) Aprendizagem de alunos surdos

2) Aprendizagem expansiva

3) Aprendizagem significativa

4) Aprendizagem situada

5) Autorregulação da aprendizagem

6) Educação matemática crítica

7) Erro

8) Escrita

9) Estrutura das práticas sociais

10) Etnomatemática

11) Fatores emocionais

12) História da matemática
13) Informática

14) Interdisciplinaridade

15) Investigação matemática

16) Jogos

17) Materiais manipuláveis

18) Modelagem matemática

19) Narrativas

20) Objetos de aprendizagem

21) Relações docente com o saber matemático

22) Resolução de problemas

23) Tarefas investigativas

24) Trabalho colaborativo

- Exemplo 1 - relativo à Modelagem Matemática - do periódico Gepem n. 6420141 (extrato retirado do miolo do artigo e referência descrita ao final do artigo)

É importante destacar também que o uso da modelagem nos anos iniciais do ensino fundamental pode desenvolver aspectos como interação, motivação, contextualização, problematização; interdisciplinaridade e diálogo investigativo, que podem contribuir com a aprendizagem da matemática pelas crianças desde a fase inicial da sua escolaridade (SILVA; KLÜBER, 2011). Grifos nossos.

SILVA, V.S; KLUBER, T. E. Um olhar pedagógico sobre a Modelagem Matemática nas séries iniciais do Ensino Fundamental. In: SEMINÁRIO DE PEDAGOGIA. 2., 2011, Irati. Anais [...]. Irati: Departamento de Pedagogia da Universidade Estadual do Centro-Oeste, 2011.

- $\quad$ Exemplo 2 - relativo à Resolução de Problemas - do periódico Bolema v. 27 n. 4620138 (extrato retirado do miolo do artigo e referência descrita ao final do artigo)

Adotamos a metodologia do ensino de Matemática através da resolução de problemas (ALLEVATO; ONUCHIC, 2009) para o planejamento das tarefas de ensino de simetria e seu desenvolvimento em sala de aula. Assumir tal metodologia foi significativo, uma vez que a resolução de problemas traz grande potencialidade para a aprendizagem geométrica, permitindo uma participação ativa do aluno que é levado a assumir a corresponsabilidade por sua aprendizagem. Grifos nossos.

ALLEVATO, N. S. G.; ONUCHIC, L. R. Ensinando matemática na sala de aula através da resolução de problemas. Boletim GEPEM, Rio de Janeiro, v.33, n.55, p.133-156, jul./dez. 2009.

Na área de Educação/Ensino, a partir da leitura "flutuante” nos fragmentos textuais selecionados durante a tomada de dados nas revistas Cedes, Ciência \& Educação e Ensaio, também se pode notar essa variedade de contexto e/ou cenários investigativos. A seguir são listados os que emergiram das análises dos trechos dos artigos que fazem parte desse corpus. Mantendo o mesmo padrão de apresentação dois exemplos são expostos na continuidade. 

1) Alfabetização
2) Analogias
3) Aprendizagem de alunos surdos
4) Aprendizagem informal e não formal
5)Aprendizagem por livre escolha
6) Aprendizagem significativa
7) Aspectos epistemológicos e ontológicos
8) Atividades investigativas
9) Avaliação
10) Ciclos de aprendizagem
11) CTSA (Ciência, Tecnologia, Sociedade, Ambiente)
12) Educação de jovens e adultos
13) Educação inclusiva
14) Educação na prisão
15) Experimentação

16) Focos da aprendizagem científica

17) Formação de professores

18) História de vida

19) História e filosofia da ciência

20) Informática

21) Linguagem científica

22) Literatura

23) Livro didático

24) Modelagem

25) Neuroeducação

26) Objetos de aprendizagem

27) Preconcepções

28) Produção de texto

29) Projetos colaborativos

30) Resolução de problemas

31) Tempo de aprendizagem

- Exemplo 1 - relativo à Alfabetização - do periódico Cedes v. 33 n. 8920131 (extrato retirado do miolo do artigo e referência descrita ao final do artigo)

Como se sabe, porém, nas iniciativas para se alcançar essa aprendizagem básica, estão envolvidos interesses diversos, já que a alfabetização é um problema sistematicamente estratégico do "longo século XX" (SAVIANI, 2006) educacional brasileiro e "[...] continua sendo um dos signos mais evidentes e complexos da ambígua relação entre deveres do Estado e direitos do cidadão”. Grifos nossos.

SAVIANI, D. O legado educacional do "longo século XX" brasileiro. In: SAVIANI, D. et al. O legado educacional do século XX no Brasil. 2. ed. Campinas: Autores Associados, 2006.

- Exemplo 2 - relativo à Aprendizagem de alunos surdos - do periódico Ciedu v. 21 n. 02 20154 (extrato retirado do miolo do artigo e referências descritas ao final do artigo)

Se o conhecimento científico deve ser alvo de aprendizado de todos - princípios estes norteados pela alfabetização científica (CACHAPUZ et al., 2005; CHASSOT, 2003), então, ele deve ser alvo de aprendizado, também, dos alunos surdos, para que possam exercer sua cidadania. Grifos nossos.

CACHAPUZ, A. et al. (org.). A necessária renovação do ensino de ciências. São Paulo: Cortez, 2005.

CHASSOT, A. Alfabetização científica, questões e desafios para a educação. 3. ed. Ijuí: Unijuí, 2003.

A partir da metodologia utilizada, dos dados selecionados e dos resultados encontrados neste percurso investigativo, pode-se observar que, atualmente, no Brasil, não existem, em geral, referências e nem autores que se destacam como representativos em teorias de aprendizagem na área de Educação Matemática e na área de Educação/Ensino. Contudo, ao restringir-se o contexto/cenário em que os resultados das pesquisas são apresentados nos artigos inventariados, talvez se possa inferir determinada representatividade de referências e de autores, mas essa indagação se constitui em outra questão de pesquisa estruturante de uma busca vindoura. 


\title{
CONSIDERAÇÕES FINAIS
}

Como já descrito, esta pesquisa foi idealizada para buscar referências que pudessem ancorar a aprendizagem da matemática atualmente no Brasil e, também, as referências que fundamentassem o campo da aprendizagem na área de Educação/Ensino.

Um pouco mais de um quarto dos artigos publicados nas revistas selecionadas enfatizaram a aprendizagem, ratificando a importância do tema na área educacional. Contudo, a partir das verificações realizadas, em relação à frequência das referências e dos autores, e o teste de diferença entre proporções, constatou-se que nenhuma referência e autor se destacam de forma significativa, cujos percentuais são muito baixos em relação ao total de referências e autores citados. A partir desse panorama, não foi possível encontrar referências e autores que se destacassem como representativos para a criação de um aporte teórico sobre aprendizagem nas áreas selecionadas.

Nota-se que essa divergência de referências e autores no campo da aprendizagem pode se dar pelo fato de as pesquisas ocorrerem em uma diversidade de contextos, em que cada um possui seu arcabouço teórico para estudar a aprendizagem.

Como não foi encontrada uma representatividade de referências e autores, não ocorreu a fase da análise de conteúdo referente à categorização dos dados, ou seja, não se agrupou os dados mediante critérios definidos durante o processo de desenvolvimento da investigação. Na parte da diversidade de contextos investigativos, como não é de interesse desta investigação, também não se investiu na categorização dos dados.

A partir de algumas reflexões sobre os resultados encontrados pode-se inferir que, se fosse analisada a concepção de aprendizagem que os autores selecionados nesta investigação relataram em seus artigos, talvez, vários autores, mesmo que trabalhando em contextos diferentes, tenham como suporte teórico teorias de aprendizagem que estão fundamentadas em uma mesma corrente filosófica.

\begin{abstract}
Subjacentes às teorias estão sistemas de valores que se pode chamar de filosofias ou visões de mundo. No caso das teorias de aprendizagem, são três as filosofias subjacentes - a comportamentalista (behaviorismo), a humanista e a cognitivista (construtivismo) - embora nem sempre se possa enquadrar claramente determinada teoria de aprendizagem em apenas uma corrente filosófica. (grifos do autor) (MOREIRA, 2011, p. 13).
\end{abstract}

Todavia, esse questionamento também não se constitui como pergunta estruturante desta investigação, mas poderá se estabelecer como tal em trabalhos venturos.

De certa forma, em outra reflexão a respeito desta investigação, pode-se dizer que, em parte, realizou-se uma análise do pensamento investigativo dos pesquisadores que tiveram seus artigos publicados nas revistas selecionadas, considerando as ideias de pensamento científico convergente e divergente de Kuhn (2011), como inspiradoras desta analogia sobre o pensamento investigativo.

De acordo com Kuhn (2011, p. 276), "os pensamentos divergente e convergente, mesmo estando em conflito”, são igualmente necessários ao avanço científico. A tensão gerada por esse conflito é um requisito importante para a pesquisa científica. Segundo o autor, as investigações normais possuem a característica de serem convergentes, ou seja, são fundamentadas em uma conformidade proporcionada pela educação científica e fortalecida pela vida do profissional.

Essa característica se encontra no pensamento investigativo quando se observa a aprendizagem em um contexto específico, seja ele na Educação Matemática e/ou na Educação/Ensino. Quando se olha os grupos separados, cada um tem o pensamento convergente sobre aprendizagem a partir do contexto trabalhado, esse pensamento está em conformidade com os pesquisadores que trabalham no mesmo contexto e com a vida profissional deles. Cada um tem suas convergências.

Contudo, quando se olha a área como um todo, as divergências pulsam pelo fato de não se encontrar referência e autor que se destacam de forma significativa. Com o levantamento realizado e 
as considerações a que se chegou deu-se uma cor diferente a essa divergência, ou seja, foi possível evidenciar que a área de Educação Matemática e Educação/Ensino divergem quando se busca tendências nas referências ou nos autores sobre a temática aprendizagem e suas teorias.

\section{REFERENCIAS}

BAMPI, L. R. et al. Em meio ao Pibid e aos estágios de docência - da escrita na leitura. Zetetiké, Campinas,v. 21, n. 40, p.105-125, maio 2013.

BARDIN, L. Análise de conteúdo. Lisboa: Edições 70, 2011.

FERREIRA, N. S. A. As pesquisas denominadas "Estado da Arte". Educação \& Sociedade, Campinas, v. 23, n. 79, ago. 2002.

GARNICA, A. V. M.; PEREIRA, M. E. F. A pesquisa em Educação Matemática no Estado de São Paulo: um possível perfil. Bolema: Boletim de Educação Matemática/Instituto de Geociências e Ciências Exatas. Departamento de Matemática, Rio Claro, v. 11, n.12, p. 59-74, 1996.

KUHN, T. S. A tensão essencial. São Paulo: Unesp, 2011.

MORAES, R. Análise de conteúdo. Revista Educação, Porto Alegre, v. 22, n. 37, p. 7-31, 1999.

MORAES, R. Uma tempestade de luz: a compreensão possibilitada pela análise textual discursiva. Ciência \& Educação, Bauru, v. 9, n. 2, p.191-211, jun./ dez. 2003. Disponível em: http://www.scielo.br/pdf/ciedu/v9n2/04.pdf. Acesso em: 17 jun. 2016.

MOREIRA, M. A. Teorias de aprendizagem. São Paulo: EPU, 2011.

NAVARRO, P.; DÍAZ, C. Análisis de contenido. In.: DELGADO, J. M.; GUTIÉRREZ, J. (coord.). Métodos y técnicas cualitativas de investigación en ciencias sociales. Madrid: Síntesis, 1999.

PASSOS, A. M. Um estudo sobre a formação de professores de Ciência e Matemática. Dissertação (Mestrado em Ensino de Ciências e Educação Matemática) - Universidade estadual de Londrina, Londrina, 2009b. Disponível em: http://www.bibliotecadigital.uel.br/document/?code =vtls000151196. Acesso em: 17 jun. 2016.

PASSOS, M. M. O professor de matemática e sua formação: análise de três décadas da produção bibliográfica em periódicos na área de Educação Matemática no Brasil. Tese (Doutorado) Universidade Estadual Paulista - Unesp, Faculdade de Ciências. Bauru, 2009a. Disponível em: https://repositorio.unesp.br/bitstream/handle/11449/102016/passos_mm_dr_bauru.pdf?sequence=1. Acesso em: 17 jun. 2016

\section{AGRADECIMENTOS:}

À Fundação Araucária e ao Conselho Nacional de Desenvolvimento Científico e Tecnológico (CNPq) pelo apoio financeiro. 